\title{
Preparation of Cerium-rich Rare Earth Oxide Nanoparticles from Bastnaesite Concentrate
}

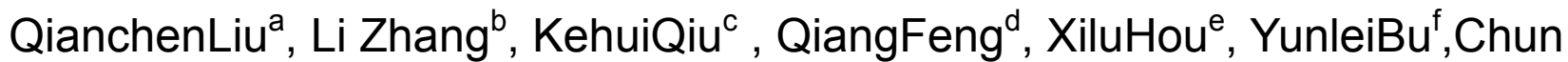 \\ $\mathrm{Hu}^{\mathrm{g}}$
}

\author{
Institute of Materials Science and Technology, Chengdu University of Technology, Chengdu \\ 610059, China
}
a18235130480@163.com, bzhanglixmu@163.com, 'qkh2188@163.com, 'fq520ww@yahoo.com, e15828293524@163.com, buyunlei381410@163.com, ${ }^{9}$ m18780260504@163.com

\begin{abstract}
Keywords: bastnaesite, alkali fusion, ceria nanoparticles, the grade of cerium oxide, the grade of rare earth oxides
\end{abstract}

\begin{abstract}
Cerium-rich rare earth oxides nanoparticles were extracted from bastnaesite concentrate by first leaching, alkali fusion with $\mathrm{NaOH}$, and second leaching process. The effects of the hydrochloric acid concentration, mass ratio of solid to liquid, leaching temperature of the leaching process, and the $\mathrm{NaOH}$ amount, roasting temperature and roasting time of alkali fusion process were systematically studied by X-ray fluorescence spectrometry (XRF), X-ray diffraction (XRD) and transmission electron microscope (TEM) analysis. The optimum parameters of the leaching process were $2 \mathrm{~mol} \cdot \mathrm{L}^{-1} \mathrm{HCl}$ solution, solid to liquid mass ratio 1: 5 and $75{ }^{\circ} \mathrm{C}$, respectively. Nonrare earth impurities could be effectively removed by roasting the first sludge with $30 \mathrm{wt} . \% \mathrm{NaOH}$. The grade of total rare earth oxides and the purity of $\mathrm{CeO}_{2}$ in the final product were $96.99 \%$ and $78.73 \%$, respectively, which were improved by $10.62 \%$ and $5.73 \%$ than that of one step leaching. The cerium-rich rare earth oxides powder showed a major phase of ceria, with particle size distribution of $20 \sim 100 \mathrm{~nm}$ according to TEM.
\end{abstract}

\section{Introduction}

Cerium oxide is a rare earth oxide with special physical and chemical properties. At present it has been widely used in chemicalmachine polishing(CMP), catalysts, ultravioletblocker, opticaldevices, ceramic, fuel cells and so on. Because of itsexcellent cutting ability, short polishing time, high polishingprecision, clean operating environment, and better effect compared with the other polishing powders $[1,2]$, cerium oxideis especially considered candidate in the field of CMP.

Usually cerium oxideis prepared by two ways: liquid phase method and extracting from bastnaesite. The advantage of liquid method is obvious, small particle size and high purity cerium oxide can be easily obtained underambient condition with cerium salts, such as sol-gel method, hydrothermal method and micro-emulsion method. However, the grain coarsening and aggregation in liquid phase usually lead to inhomogeneous powders, and expensive raw material and sophisticated production equipment make the industrialization difficult $[3,4]$.

The other important way to obtain cerium oxide is directly extracted from the bastnaesite.As amain industrial mineral, bastnasite is the largestproven reserveamongallrare earth (RE) minerals in theworld [5]. For example, rich resources of bastnaesitewere found in Mianning, Sichuan and Huishan, Shandong in China[6-8]. Zhou Jing etal.[9]roastedbastnaesite with auxiliary agent, and leached the cerium with sulfuric acid after washing the calcine with water. The cerium (IV)and other RE elements wereseparated by P204 extraction, and cerium product was obtained by washing and reverse extraction. Liu Zhaogangetal.[10] Roasted the bastnaesite with sodium carbonate and washed out $\mathrm{NaF}$ with water. The cerium (IV) was separated from other RE elements by leaching with dilute hydrochloric acid, and the sludge was the Ce rich concentrate. R. CHI etal. [11] leached the sludge with concentratedhydrochloricacid and hydrogenperoxide, high-puritycerium (IV) oxidewas recoveredfrom the leachate by precipitationusing oxalic acidand roasting, in which $\mathrm{CeO}_{2} / \sum \mathrm{REO}>95 \%$, and the recovery of cerium is $85.3 \%$. 
Hui Zhong[12] put forward a new roasting decomposition method of bastnaesite in $\mathrm{NaHCO}_{3}$. After washing the $\mathrm{NaF}$ using water, the sludge was leached with dilutehydrochloricacid $\left(3 \mathrm{~mol} \cdot \mathrm{L}^{-1}\right)$ to separate cerium oxide from trivalent RE elements, calcium and iron etc. The purity of cerium oxide reached $72 \%$ in the product by thismethod, however, the factors in leaching process were not optimized. In this paper, we improved Zhong's method. The sludge of first leaching was roasted with $\mathrm{NaOH}$, then the calcinate was leached again to enhance the purity of cerium oxide and the grade of rare earth in the product, and the factors in the first leaching process were studied in detail.

\section{Experimental}

\subsection{Materials}

The bastnasite concentrate in the experiment was fromDechang,located in the Sichuan province in China.The mineral material was crushed and sieved to $0.075 \mathrm{~mm}$, and main compositions were shown in the Table 1 . The total rare earth oxide was 57.43 wt. \%, and $\mathrm{CeO}_{2}$ was 30.29 wt.\%.

Table1. Main Chemical Compositions ofBastnaesite Concentrate (wt.\%).

\begin{tabular}{ccccccc}
\hline Compositions & $\mathrm{CeO}_{2}$ & $\mathrm{La}_{2} \mathrm{O}_{3}$ & $\mathrm{Nd}_{2} \mathrm{O}_{3}$ & $\mathrm{Fe}_{2} \mathrm{O}_{3}$ & $\mathrm{CaO}$ & $\mathrm{SiO}_{2}$ \\
Percentage & 30.29 & 20.68 & 6.46 & 6.53 & 7.71 & 5.66 \\
\hline Compositions & $\mathrm{SrO}$ & $\mathrm{Al}_{2} \mathrm{O}_{3}$ & $\mathrm{SO}_{3}$ & $\mathrm{BaO}$ & $\mathrm{F}$ & Others \\
Percentage & 4.13 & 2.06 & 4.80 & 1.90 & 8.29 & 1.49 \\
\hline
\end{tabular}

\subsection{Methods}

$20 \mathrm{~g}$ bastnasite concentrate was mixed well with $4 \mathrm{~g} \mathrm{NaHCO}_{3}$, and roasted at $600{ }^{\circ} \mathrm{C}$ for two hours. Thecalcinatewaswashed with water to remove $\mathrm{Na}_{2} \mathrm{CO}_{3}$, NaFetc, thenleached with concentrated hydrochloric acid.The sludge was roasted with $\mathrm{NaOH}$ in a muffle furnace, and washed with dilute $\mathrm{HCl}$ for second time. Finally rare earth oxide rich in cerium was obtained by roasting the second sludge.

The reactions during the roasting decompositionin $\mathrm{NaHCO}_{3}$ were shown as fomular 1-4.

$$
\begin{aligned}
& 2 \mathrm{NaHCO}_{3}=\mathrm{Na}_{2} \mathrm{CO}_{3}+\mathrm{H}_{2} \mathrm{O}+\mathrm{CO}_{2}(1) \\
& \mathrm{RECO} \mathrm{O}_{3} \mathrm{~F}=\mathrm{REOF}+\mathrm{CO}_{2} \\
& \mathrm{Na}_{2} \mathrm{CO}_{3}+\mathrm{REOF}=\mathrm{REO}_{1+x} \mathrm{~F}_{1-x}+\mathrm{NaF}+\mathrm{CO}_{2} \\
& 2 \mathrm{CeFCO}_{3}+\mathrm{Na}_{2} \mathrm{CO}_{3}+1 / 2 \mathrm{O}_{2}=2 \mathrm{CeO}_{2}+2 \mathrm{NaF}+3 \mathrm{CO}_{2}
\end{aligned}
$$

The main reactions in the first leaching process were shown as fomular5,6. $\mathrm{RE}_{2} \mathrm{O}_{3}+6 \mathrm{HCl}=2 \mathrm{RECl}_{3}+3 \mathrm{H}_{2} \mathrm{O}$

\subsection{Analysis}

$$
2 \mathrm{CeO}_{2}+8 \mathrm{HCl}=2 \mathrm{CeCl}_{3}+4 \mathrm{H}_{2} \mathrm{O}+\mathrm{Cl}_{2}
$$

X-ray diffraction (XRD) analysis of the sampleswere performed on a X-ray diffractometer (Fang Yuan, DX-2700) with $\mathrm{CuK} \alpha$ radiation $(30 \mathrm{~mA}, 40 \mathrm{kV}, \lambda=0.154184 \mathrm{~nm})$ in the 29range from $20^{\circ}$ to $72^{\circ}$. The compositions of the sludgeswere determined by X-ray fluorescence spectrometry(XRF, Shiadzu, XRF-1800) with a rhodium tube as the source of radiation (4kW, 85mA).The morphology and size of product were characterized by transmissionelectron microscope (TEM, Carl Zeiss Libra 200FE).

Thegrade of total rareearth oxidesand the purity of cerium oxide in the sludge were expressed by $\sum \mathrm{REO}$ and $w_{1}\left(\mathrm{CeO}_{2}\right)$, respectively, as shown in formula 7 and 8 . The grade of cerium oxide was expressed by $\mathrm{CeO}_{2} / \sum \mathrm{REO}$, which was calculated base on the grade of total rare earth oxides in thesludge (formula9). The recovery of cerium was expressed by theformula 10,in which $m_{0}$ and $w_{0}$ were the mass and cerium purity of the bastnasite concentrate, $m_{l}$ and $w_{l}$ were the mass and cerium purity of the sludge, respectively.

$$
\begin{aligned}
& \sum R E O=\frac{m(\text { REO })}{m(\text { sludge })} \times 100 \% \\
& w_{1}\left(\mathrm{CeO}_{2}\right)=\frac{m\left(\mathrm{CeO}_{2}\right)}{m(\text { sludge })} \times 100 \% \\
& \mathrm{CeO}_{2} / \sum R E O=\frac{m\left(\mathrm{CeO}_{2}\right)}{m(\mathrm{REO})} \times 100 \%
\end{aligned}
$$




$$
x(\mathrm{Ce})=\frac{m_{1} w_{1}}{m_{0} w_{0}} \times 100 \%
$$

\section{Results and discussion}

\subsection{Factorsin leaching}

After being roasted with $\mathrm{NaHCO}_{3}$ and washed with water, the calcinate was leached with concentrated hydrochloric acid to dissolve impurities and improve the purity of product. The effects of the hydrochloricacid concentration, the mass ratio of solid to liquid and theleaching temperature on the grade of cerium oxide $\left(\mathrm{CeO}_{2} / \sum \mathrm{REO}\right)$ and total rare earth oxides $\left(\sum \mathrm{REO}\right)$ were studied.

\subsubsection{Thehydrochloricacid concentration}

The effect of $\mathrm{HCl}$ concentration on the grade of cerium oxide $\left(\mathrm{CeO}_{2} / \sum \mathrm{REO}\right)$ and the grade oftotal rare earth oxides ( $\sum \mathrm{REO}$ ) were shown in Fig.1. With $\mathrm{HCl}$ concentration increasing, $\mathrm{CeO}_{2} / \sum \mathrm{REO}$ increased from $69.84 \mathrm{wt} \%$ to $93.46 \mathrm{wt} . \%$, which was due to thetrivalent rare earthsdissolved in $\mathrm{HCl}$ solution in the form of $\mathrm{RECl}_{3}$ (equation 5), and most $\mathrm{CeO}_{2}$ remained in the leach sludge. For the dilute $\mathrm{HCl}$ solution $\left(<2 \mathrm{~mol} \cdot \mathrm{L}^{-1}\right)$, the $\sum \mathrm{REO}$ in the sludge remained about 82 wt. \%. However, when the $\mathrm{HCl}$ concentrationwas higher than $2 \mathrm{~mol} \cdot \mathrm{L}^{-1}$, $\sum \mathrm{REO}$ reduced obviously. For $3 \mathrm{~mol} \cdot \mathrm{L}^{-1} \mathrm{HClsolution,} \sum \mathrm{REO}$ was only $64.31 \mathrm{wt} \% . \mathrm{CeO}_{2}$ as well as other rare earth oxides reacted with high concentration $\mathrm{HCl}$ solution, and dissolved in the formof $\mathrm{CeCl}_{3}$ (equation 6) [11], which resulted the loss of cerium and decrease of $\sum$ REO in the sludge. The optimal concentration of hydrochloricacid in the first leaching was chosen $2 \mathrm{~mol} \cdot \mathrm{L}^{-1}$, considering the grade of cerium oxide and the grade oftotal rare earth oxides.
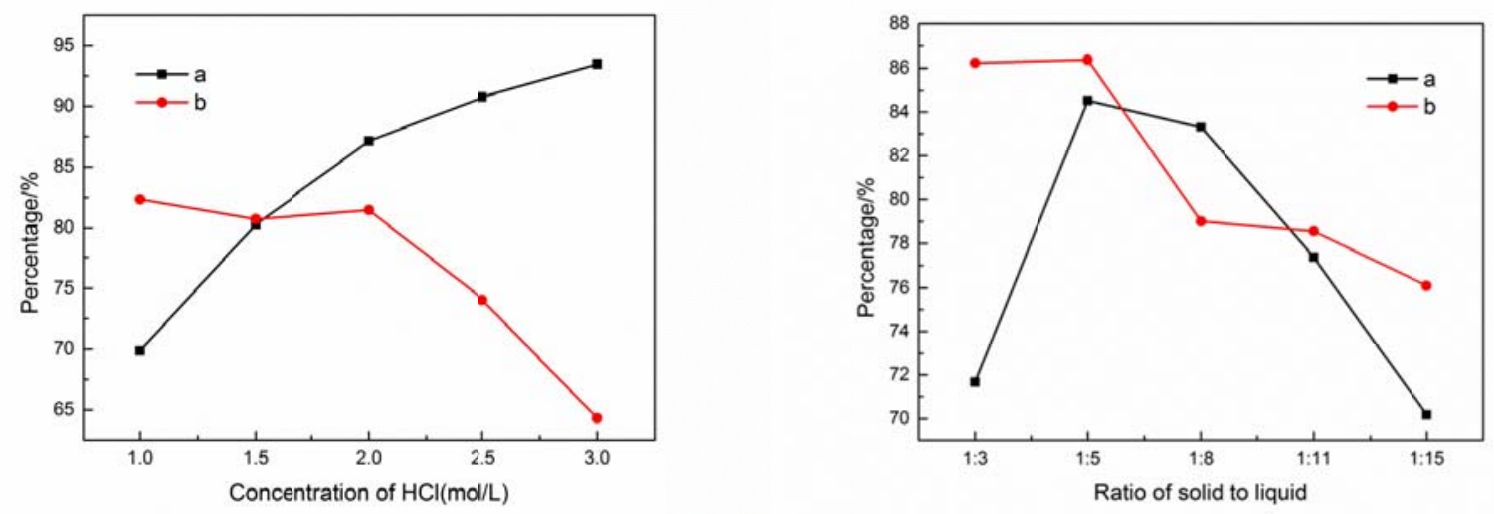

Fig.1.Effect of the hydrochloric acid concentrationonFig.2.Effect of the mass ratio of solid to liquid on

(a) $\mathrm{CeO}_{2} / \sum \mathrm{REO}$ and (b) $\sum \mathrm{REO}\left(45^{\circ} \mathrm{C}, 1 \mathrm{~h}\right.$, mass (a) $\mathrm{CeO}_{2} / \sum \mathrm{REO}$ and (b) $\sum \mathrm{REO}\left(75^{\circ} \mathrm{C}, 1 \mathrm{~h}\right.$, ratio of solid to liquid $1: 5) \cdot 2 \mathrm{~mol} \cdot \mathrm{L}^{-1} \mathrm{HCl}$ ).

\subsubsection{Mass ratio of solid to liquid}

Besides concentration, the amount of $\mathrm{HCl}$ solution was also taken into consideration. The effect of the mass ratio of solid to liquid on $\mathrm{CeO}_{2} / \sum$ REO and $\sum$ REO were shown in Fig.2. 2 REOdecreases gradually with the decreasing of solid to liquidfrom 1:3 to $1: 15$, which was due to more rare earths elements dissolving into hydrochloric acidsolution. However, $\mathrm{CeO}_{2} / \sum \mathrm{REO}$ first increases and then decreases, which reaches the largest grade at the mass ratio 1:5. Base on the rare earth oxides of bastnasite concentrate, hydrochloric aciddosagewas not enough to dissolve all the rare earths at mass ratio 1:3, so trivalent non-Ce rare earths were mainly leached (reaction 5) and most of Ce remained as $\mathrm{CeO}_{2}$ in the sludge. However, with more $\mathrm{HCl}$ solution used, $\mathrm{CeO}_{2}$ reacted with the high dosage hydrochloric acid and formed $\mathrm{CeCl}_{3}$ dissolving in the solution, leading to the decrease of $\mathrm{CeO}_{2} / \sum \mathrm{REO}$ in the sludge. Thus, the optimal ratio of solid to liquid was 1:5.

\subsubsection{Leaching temperature}

The effect of leaching temperature on $\mathrm{CeO}_{2} / \sum \mathrm{REO}$ and $\sum \mathrm{REO}$ were shown in Fig.3. When leaching solution was heated, $\sum$ REOin the sludge first rose and then decreased, and reached the maximum at $75{ }^{\circ} \mathrm{C}$. The reason was the non-rare earth impurities reacted with hydrochloric acidsignificantly with the temperature rising, which was leached in the solution. However, the 
volatilization of hydrochloric acid gas became more and more obvious when the reacting temperature above $75^{\circ} \mathrm{C}$. $\mathrm{CeO}_{2} / \sum \mathrm{REO}$ presented a downward trend with the increasing temperature, because more cerium dissolved in solution in the form of $\mathrm{CeCl}_{3}$ with the oxidation ability of $\mathrm{CeO}_{2}$ increased as the temperature rising, resulting in $\mathrm{CeO}_{2} / \sum \mathrm{REO}$ gradually decreases. Therefore, $75^{\circ} \mathrm{C}$ was chosen as the optimum temperature in the leaching process.

In conclusion, in the first leaching process, hydrochloricacid concentration and the mass ratio of solid to liquid showed significant influence on $\mathrm{CeO}_{2} / \sum \mathrm{REO}$ and $\sum \mathrm{REO}$ than temperature. Under the optimal conditions, $\sum \mathrm{REO}$ and $\mathrm{CeO}_{2} / \sum \mathrm{REO}$ could reach $86.37 \mathrm{wt} \%$ and $84.52 \mathrm{wt} \%$, respectively, while the recovery of cerium was $84.03 \%$, which was obviously enhancedthan Zhong's work[12].

\subsection{Alkali fusion}

The sludge of first leaching was roasted with $\mathrm{NaOH}$, and then experienced second hydrochloricacid leaching to further purify. In the process of alkali fusion, the $\mathrm{NaOH}$ amount, roasting temperature and roasting time were studied, and the $\mathrm{NaOH}$ amount was the key factor according to the study.
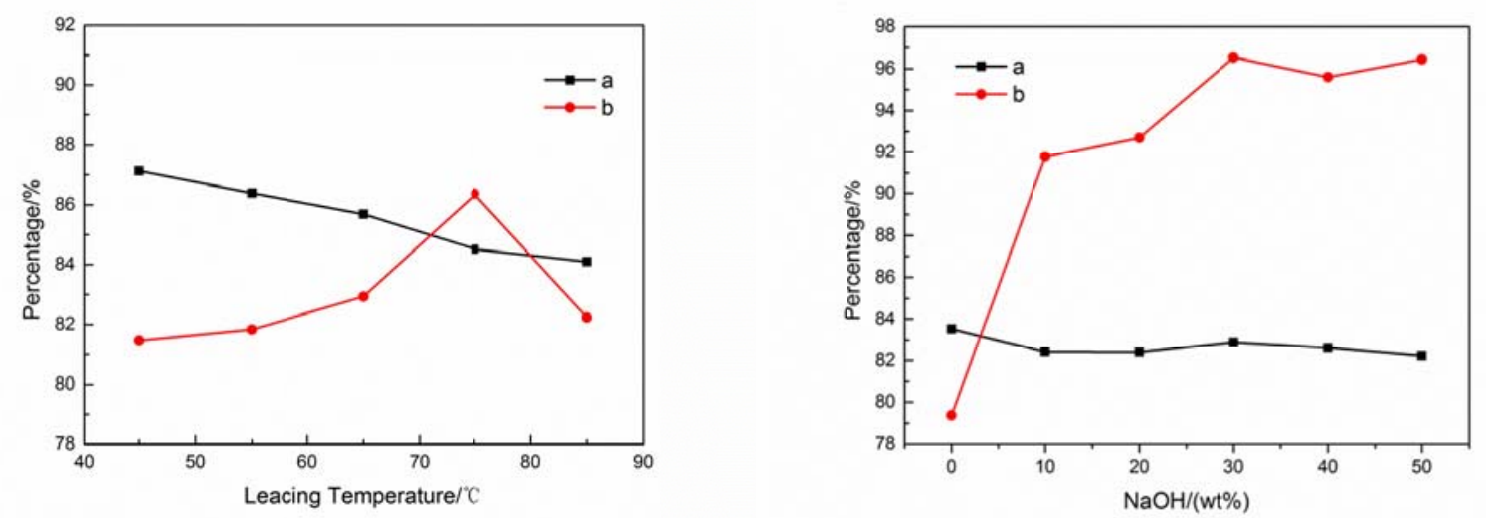

Fig.3.Effect of leaching temperature on (a) $\mathrm{CeO}_{2} / \sum$ REOFig.4.Effect of $\mathrm{NaOHon}$ (a) $\mathrm{CeO}_{2} / \sum \mathrm{REO}$ and (b) $\sum$ REO $\left(2 \mathrm{~mol} \cdot \mathrm{L}^{-1} \mathrm{HCl}, 1 \mathrm{~h}\right.$, ratio of solid to liquid and (b) $\sum \mathrm{REO}\left(600{ }^{\circ} \mathrm{C}, 1 \mathrm{~h}\right)$.

$1: 5)$.

\subsubsection{Effect of $\mathrm{NaOH}$ amount}

The effect of the $\mathrm{NaOH}$ amount on the grade of cerium oxide $\left(\mathrm{CeO}_{2} / \sum \mathrm{REO}\right)$ and total rare earth oxides ( $\sum$ REO) were shown in Fig.4.The addition of $10 \mathrm{wt} . \% \mathrm{NaOH}$ into first sludge resulted in an increase of $\sum$ REO, $91.77 \%$ compared with $79.37 \%$ of first sludge. This demonstrated the process of alkali fusionefficiently reduced the non-rare earth impurities, which was due to the reaction between the non-rare earth impurities and $\mathrm{NaOH}$.

$\sum$ REOin sludge enhanced with the $\mathrm{NaOH}$ amount increasing, and reached the maximum of 96.53 wt. $\%$ at 30 wt. \% addition.More $\mathrm{NaOH}$ amount was not necessary for no obvious increase of $\sum$ REO. $\mathrm{CeO}_{2} / \sum$ REOwas almost unchanged with the variationof the $\mathrm{NaOH}$ amount. Thus, the optimal $\mathrm{NaOH}$ amount was $30 \%$.

The content of the main chemical compositions of sludges before and after alkali fusiontreatment with 30 wt. $\% \mathrm{NaOH}$ additionwas shown in table 2.The content of rare earth oxides $\mathrm{CeO}_{2}, \mathrm{La}_{2} \mathrm{O}_{3}$ and $\mathrm{Nd}_{2} \mathrm{O}_{3}$ increased significantly compared with that of before, while non-rare earth impurities such as oxides of $\mathrm{Fe}, \mathrm{Si}, \mathrm{Ca}$ and $\mathrm{Sr}$ etc. decreased obviously, which indicatedthe non-rare earth impurities reacted with $\mathrm{NaOH}$ and were removed by washing, resulting in the remarkableincrease of $\sum$ REO. Aluminosilicate, as the common impuritiesin bastnaesite, could react with $\mathrm{NaOH}$ to form water soluble salts, as shown formula 11 and12. According to the report of literature [13], fluorite $\left(\mathrm{CaF}_{2}\right)$ could also react with $\mathrm{NaOH}$ to form $\mathrm{Ca}(\mathrm{OH})_{2}$ (formula 13$)$, when calcinatedat high temperature, so as the alkali earth metal $\mathrm{Ba}$.

$$
\begin{gathered}
\mathrm{Al}_{2} \mathrm{O}_{3}+2 \mathrm{NaOH}^{2} 2 \mathrm{NaAlO}_{2}+\mathrm{H}_{2} \mathrm{O}(11) \\
\mathrm{SiO}_{2}+2 \mathrm{NaOH}=\mathrm{Na}_{2} \mathrm{SiO}_{3}+\mathrm{H}_{2} \mathrm{O}(12) \\
\mathrm{CaF}_{2}+2 \mathrm{NaOH}=\mathrm{Ca}(\mathrm{OH})_{2}+2 \mathrm{NaF}
\end{gathered}
$$

Therefore, the fluorite, the oxides, and the sulfateswhichremained in the first sludge could be 
leached in the second leaching after alkali fusion, and the $\sum$ REOenhanced.

The XRD patterns of sludge before and after alkali fusionwere shown in Fig.5. The major phasesbefore alkali fusionwere $\mathrm{CeO}_{2}$ and $\mathrm{CeF}_{3}$, however, NaFappearedand $\mathrm{CeF}_{3}$ disappeared after alkali fusion. This impliedthe reactions took place in the process of alkali fusion, as formula 14, 15.

$$
\begin{aligned}
& \mathrm{CeF}_{3}+3 \mathrm{NaOH}=\mathrm{Ce}(\mathrm{OH})_{3}+3 \mathrm{NaF} \\
& \mathrm{Ce}(\mathrm{OH})_{3}+1 / 2 \mathrm{O}_{2}=\mathrm{CeO}_{2}+\mathrm{H}_{2} \mathrm{O}
\end{aligned}
$$

In conclusion, alkali fusion significantly reduced the non-rare earth impurities, thereby $\sum \mathrm{REO}$ and $\mathrm{CeO}_{2} / \sum \mathrm{REOwere}$ both enhanced.

Table2.Main Chemical Compositions of Sludge before and after Alkali Fusion (wt.\%).

\begin{tabular}{ccccccccccc}
\hline Compositions & $\mathrm{CeO}_{2}$ & $\mathrm{La}_{2} \mathrm{O}_{3}$ & $\mathrm{Nd}_{2} \mathrm{O}_{3}$ & $\mathrm{Fe}_{2} \mathrm{O}_{3}$ & $\mathrm{SiO}_{2}$ & $\mathrm{CaO}$ & $\mathrm{SrO}$ & $\mathrm{Al}_{2} \mathrm{O}_{3}$ & $\mathrm{SO}_{3}$ & $\mathrm{BaO}$ \\
\hline $\begin{array}{c}\text { Before alkali } \\
\text { fusion }\end{array}$ & 68.13 & 8.72 & 2.02 & 4.4 & 3.96 & 1.84 & 2.15 & 0.82 & 2.19 & 1.29 \\
After alkali fusion & 80.01 & 13.98 & 2.55 & 0.35 & 0.25 & 0.51 & 0.60 & 0.10 & 0.33 & 0.33 \\
\hline
\end{tabular}

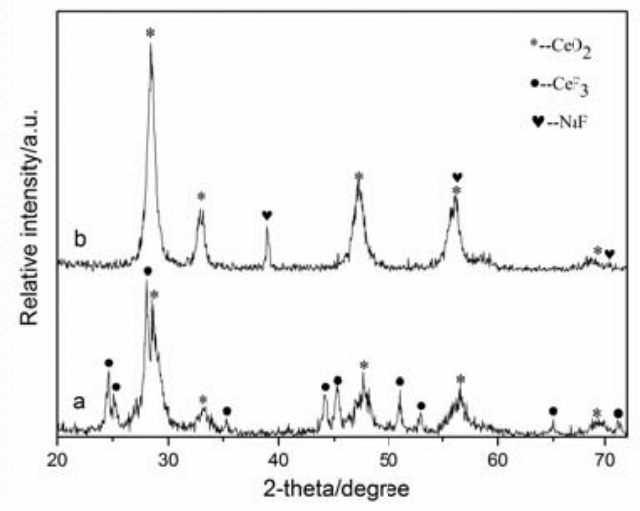

Fig.5.XRD patterns ofsludge before Alkali Fusion (a)

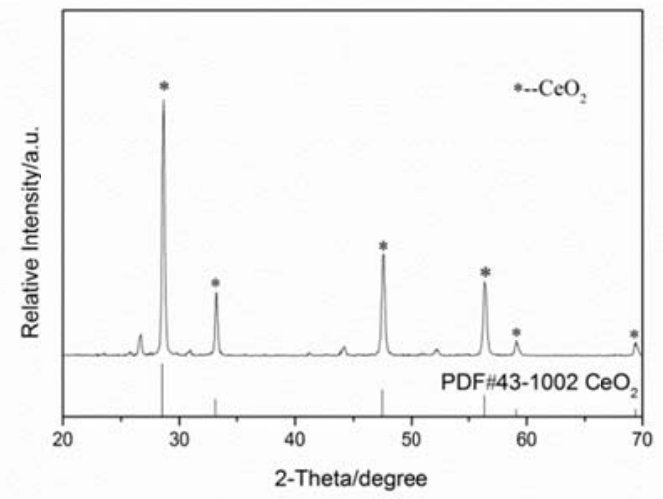

Fig.6. XRD patternof Ce-rich rare earth oxides and after Alkali Fusion (b).nanoparticles.

\subsubsection{Result of alkali fusion}

To verify the effect of the alkali fusion, $\mathrm{CeO}_{2} / \sum \mathrm{REO}, \sum \mathrm{REO}$, the recovery of cerium $(x(\mathrm{Ce}))$ and the purity of $\mathrm{CeO}_{2}\left(w_{l}\left(\mathrm{CeO}_{2}\right)\right)$ in the first and second sludge were summarized in table 3 , which sludge were obtained as the optimal conditions described above. The purity of $\mathrm{CeO}_{2}\left(w_{l}\left(\mathrm{CeO}_{2}\right)\right)$ and the grade oftotal rare earth oxides ( $\sum$ REO) after alkali fusion treatment were enhanced 5.73wt.\% and $10.62 \mathrm{wt} . \%$, respectively, while the recovery of cerium $(x(\mathrm{Ce}))$ and $\mathrm{CeO}_{2} / \sum \mathrm{REO}$ showed a little decrease comparing with that of first sludge. The main reason of the decrease in $\mathrm{CeO}_{2} / \sum \mathrm{REO}$ was the increase of $\sum$ REO. The reason of the decrease in cerium recovery was the loss in the process of alkali fusion and second leaching, however, the loss was acceptable considering the remarkable improve of purity.So, the alkali fusion and second acid leaching process was proven to be effective and necessary. 
Table3.Comparison of Sludge of first and second time (wt. \%).

\begin{tabular}{ccccc}
\hline & $\mathrm{CeO}_{2} / \sum \mathrm{REO}$ & $\sum \mathrm{REO}$ & $x(\mathrm{Cre})$ & $w_{l}\left(\mathrm{CeO}_{2}\right)$ \\
\hline Sludge of first time & 84.52 & 86.37 & 84.03 & 73.00 \\
Sludge of second time & 81.17 & 96.99 & 82.89 & 78.73 \\
\hline
\end{tabular}

\subsection{Characterization of product}

Cerium-rich rare earth oxides product was obtained by calcining the second sludge. The XRD pattern of the product was shown in Fig.6. The main diffraction peakslocated at $2 \theta=28.55^{\circ}, 33.08^{\circ}$, $47.48^{\circ}, 56.34^{\circ}, 59.09^{\circ}$ and $69.42^{\circ}$ were in good agreement with the crystal face $(111),(200),(220)$, (311), (222) and (4 00 ) of ceria, respectively, which indicatedthe major phase in the product was ceria. The particle size of the product calculated by Scherer formula was about $32 \mathrm{~nm}$. Fig. 7 shows the TEM micrograph of the product. The powders obtained were regular in equiaxed geometric contour, whichparticle size distributionwas $20 \sim 100 \mathrm{~nm}$. The surface quality of polished material was significantly influenced by the contour of ceria polishing powder. As most particles of the product showed obtuse angles, high surface quality was believed to be obtained[14].
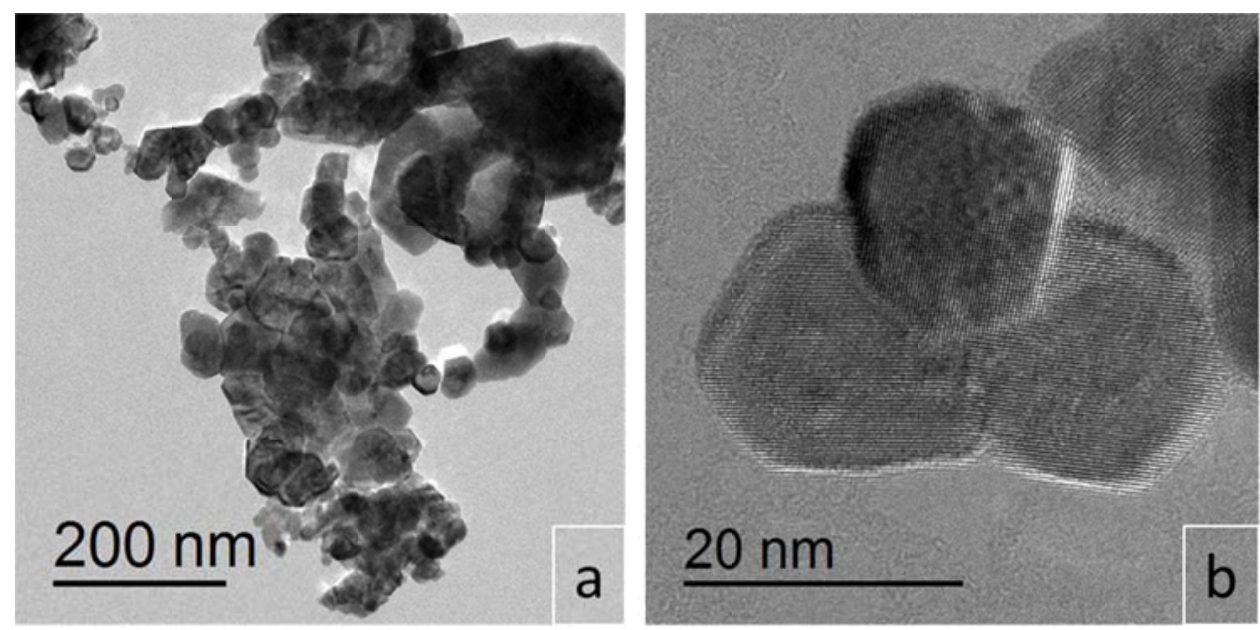

Fig.7.TEM micrographs of Ce-rich rare earth oxides nanoparticles.

\section{Conclusion}

In this paper, bastnasitewas roasted with $\mathrm{NaHCO}_{3}$, washed with water and then taken as the material. Ce-rich rare earth oxide nanoparticles powder was obtained by first leaching, alkali fusion with $\mathrm{NaOH}$, and second leaching process.

In the first leaching process, hydrochloricacid concentration and the mass ratio of solid to liquid showed significant influence on $\mathrm{CeO}_{2} / \sum \mathrm{REO}$ and $\sum \mathrm{REO}$ than leaching temperature. The optimal leaching conditions were $2 \mathrm{~mol} \cdot \mathrm{L}^{-1} \mathrm{HCl}$, solid to liquid mass ratiol:5 and $75^{\circ} \mathrm{C}$, respectively. In the process of alkali fusion, NaOHamount exhibited more effect on $\mathrm{CeO}_{2} / \sum \mathrm{REO}$ and $\sum \mathrm{REO}$ than roasting temperature and roasting time.

Thenon-rare earth impurities such as oxides of $\mathrm{Fe}, \mathrm{Si}, \mathrm{Ca}$ and $\mathrm{Sr}$ etc. were removed in the alkali fusion with $\mathrm{NaOH}$ and second leachingtreatment, resulting in the remarkable improvement of $\sum \mathrm{REO}$ and the purity of $\mathrm{CeO}_{2}$ in the product. $\sum \mathrm{REOwas}$ as high as $96.99 \%$,comparing $86.37 \%$ in the first sludge. The purity of $\mathrm{CeO}_{2}$ was $78.73 \%, 5.73 \mathrm{wt} \%$ higher than that of the first sludge. The product obtained by this method may be used as high quality polishing powder.

\section{Acknowledgments}

This work presented herein would not be possible without the Key Scientific and Technological Research and Development Program (Grantno.2014GZ0090) in Sichuan Province, PR China. We would like to acknowledge them for the financial support. 


\section{References}

[1] H.J. Liu, Z.Y. Feng, X.W. Huang, et al.Study on purification and application of novel precipitant for ceria-based polishing powder. J. Rare Earth. 31(2013) 2, 174-179.

[2] S.Hegdea, S.V.Babu,J. Electrochem. 2004. Study of surface charge effects on oxide and nitride planarization using alumina/ceria mixed abrasive slurries. J. Electrochem. Solid SZ.7(2004)12, 316.

[3] R.F. Wang, Y. Zhang.Progress in preparation of nanometer $\mathrm{CeO}_{2}$.J. Chin. Rare Earth (in Chin). 32(2011) 2, 82-86.

[4]L.Y. Xie, Z.G. Liu.Developments in preparation of nanometer $\mathrm{CeO}_{2}$.J. Chin. Rare Earth (in Chin). 28(2007) 2, 70-76.

[5]R. Chi, D. Wang. Benefication and Extraction of Rare Earth Ore. Beijing: Science Press (in Chin). 1996, 305.

[6] X. Huang.Development Trend and Research Progress of Rare Earth Extraction in China.Bulletin of National Natural Science Foundation of China (in chin). 28(2011) 3, 134-137.

[7] G.Özbayoğlu, M. ÜmitAtalay.Beneficiation of bastnaesite by a multi-gravity separator.J. Alloys.Compd, 303(2000), 520-523.

[8] Y.Q. Zhang, Y. Xu, X.W. Huang, et al. Study on thorium recovery from bastnaesite treatment process. J. Chin. Soc. RareEarth (in Chin), 30(2012) 4, 374-377.

[9] J. Zhou, C.H. Yan, C.S. Liao. Process of eliminating fluorine and extracting cerium (IV) from Mianningbastnaesite.J. Chin. Rare Earth (in Chin),19(1998)3, 9-17.

[10] Z.G. Liu, Q.S. Yang, L.S. Liu, et al.Study on the decomposition process of bastnaseite concentrate using sodium carbonate roasting followed by hydrochloric acid leaching.J. Chin. Rare Earth (in Chin), 25(2004)2, 20-25.

[11]R. Chi, Z. Li, C. Peng, et al. Preparation of enriched cerium oxide from bastnasite with hydrochloric acid by two-step leaching.Metall. Mater. Trans.B, 37(2006) 2, 155-160.

[12] H.Zhong, K.H.Qiu, Y.C.Qiu, et al. Preparation of Ceria from Bastnaesite with $\mathrm{NaHCO}_{3}$ as Fluoride Retention Additive.A. M. M,477(2013): 1423-1427.

[13] H.J. Liu: Study of the Technology for the Decomposition of Baotou Rare Earth Concentrate by Concentrated $\mathrm{NaOH}$ Solution.Master, Inner MongoliaUniversity, China.2010, 25.

[14] Q.L. Wei, Y.T.Meng, J.G.He, et al.Polishing properties of cerium oxide.Chin. J. Rare Metals (in Chin), 34(2010), 113-118. 